\title{
Sonographic guided hydrostatic saline enema reduction of childhood intussusception: a prospective study
}

\author{
Ademola Olusegun Talabi $i^{*}$, Olusola Comfort Famurewa ${ }^{2}$, Kayode Taiwo Bamigbola ${ }^{3}$, \\ Oludayo Adedapo Sowande', Babalola Ishmael Afolabi² and Olusanya Adejuyigbe ${ }^{1}$
}

\begin{abstract}
Background: The management of childhood intussusception in our sub-region is still via surgical intervention. Currently, the gold standard of treatment is non-operative reduction. We sought to assess the suitability of hydrostatic (saline) reduction of intussusception in children in our institution.

Materials and methods: A prospective study was conducted between January 2016 and June 2017 in all children with ultrasound confirmed intussusception at a tertiary teaching hospital in Nigeria. All children excluding those with signs of peritonitis, bowel gangrene and intestinal prolapse were selected for ultrasound-guided hydrostatic reduction (USGHR). We allowed a maximum of three attempts at reduction.

Results: The age range was 3 months to 48 months with a mean of $10.8 \pm 9.1$ months. Forty percent $(N=18)$ presented after $24 \mathrm{~h}$ of onset of symptoms. The success rate of hydrostatic reduction with saline enema was $84.4 \%$ $(\mathrm{N}=38)$. Two $(4.4 \%)$ perforations occurred during the procedure. Three $(7.5 \%)$ patients had recurrent intussusception within six months. The duration of symptoms greater than $24 \mathrm{~h}$, age and sex of patients did not influence successful reduction $p>0.05$. The duration of admission between those who had successful non-operative reduction and those who subsequently had operative reduction and or resection attained statistical significant difference, $p=0.001$. There was no mortality. We achieved a $68 \%$ decrease in the operative reduction of intussusception using USGHR as the primary modality of treatment.
\end{abstract}

Conclusion: Our study found out that USGHR is a suitable alternative for the treatment of childhood intussusception.

Keywords: Childhood intussusception, Hydrostatic reduction, Saline, Ultrasound-guided

\section{Background}

Intussusception is a common surgical emergency in infants and toddlers. It is also seen in older children and in adults occasionally. The incidence of intussusception is approximately one to four per 2000 infants and children $[1,2]$. Most (90\%) of the intussusception are ileocolic, while the remaining $10 \%$ are of the ileoileal or colocolic type [3].

The treatment modality in our environment is still open surgery due to late presentation of patients, misdiagnosis from peripheral health centres, dearth of modern imaging

\footnotetext{
* Correspondence: ademolatalabi1608@gmail.com

${ }^{1}$ Department of Surgery, Obafemi Awolowo University, P. O. BOX 5538, Ile-Ife, Osun State, Nigeria

Full list of author information is available at the end of the article
}

equipment such as fluoroscopic machines, and in some cases lack of expertise to undertake non-operative reduction of intussusception $[1,4]$.

Hydrostatic reduction under ultrasound guidance is a well-recognized alternative method for reduction of childhood intussusception [5]. Kim et al. [6] described the first successful sonographic guided hydrostatic reduction of intussusception in 1982. Since then, there has been widespread use of this technique due to less morbidity and mortality compared with surgical form of treatment [7]. The other non-surgical methods are reduction with barium or air under fluoroscopic guidance $[5,8]$. These other non-surgical methods of reduction under fluoroscopy are either non-existent or dysfunctional in most centres in sub Saharan Africa including our hospital [1, 9], thereby

(C) The Author(s). 2018 Open Access This article is distributed under the terms of the Creative Commons Attribution 4.0 International License (http://creativecommons.org/licenses/by/4.0/), which permits unrestricted use, distribution, and 
making ultrasound guided reduction of intussusception a better modality of treatment in resource poor environment. Ultrasound scanners are relatively cheap and readily available in most hospitals thereby rendering ultrasound guided hydrostatic reduction (USGHR) cost effective for patients. The main advantage of ultrasound guided hydrostatic reduction over reduction under fluoroscopic guidance is the avoidance of exposing young children to ionizing radiation. As ultrasound is often the first line-imaging modality for the diagnosis of intussusception, the procedure can be performed within the ultrasound room immediately after the diagnosis is made $[5,8]$. The other benefits of ultrasound guided hydrostatic reduction include less patient discomfort, shorter hospital stay, and less morbidity and mortality compared to surgical modality of treatment.

The various forms of enema in use for ultrasound guided liquid enema in use include portable tap water, normal saline or Ringers lactate solution [8, 10, 11]. In a review by Bekdash et al. [12], the overall success rate of non-operative reduction of intussusception ranged from 46 to $94 \%$, while recent studies reported that the success rate for hydrostatic reduction with saline ranges from 55.6 to $90 \%[1,13,14]$. A much more recent study from Ethiopia found a successful reduction rate of $87.2 \%$ [9].

Prior to this time, laparotomy was the only treatment option available for all cases of intussusception in our hospital with unacceptably high mortality rate of 12 to $15.4 \%[4,15]$. Subsequently, we conducted a pilot study of five consecutive children with intussusception who presented with no signs of peritonitis and other features that could preclude non-operative reduction with successful non operative reduction in all by using normal saline under ultrasound guidance.

Following our anecdotal success, we decided to conduct this study to assess the suitability of normal saline hydrostatic reduction of intussusception among children with intussusception irrespective of the age and duration of symptoms provided they meet the inclusion criteria set for non-operative reduction of intussusception in our hospital.

\section{Methods \\ Design}

This was a prospective cross sectional study of all children treated between January 2016 and June 2017 at a tertiary hospital in Nigeria.

\section{Setting}

Our institution is situated in south west, Nigeria where it provides primary and secondary health care services in addition to its main tertiary care to people who are mainly Yorubas. Majority of our population are farmers, artisans and civil servants. The paediatric surgical unit of our hospital was established in 1980 and has recently been upgraded to a 60-bedded facility to cater for children less than 16 years.

\section{Subjects and inclusion/exclusion criteria}

The ethics and research committee of our hospital approved the study. Patients who presented to the children emergency unit of our hospital were recruited into the study. All parents or guidance of the patients with suspected intussusception were informed about the procedure and they signed written informed consent to participate in the study in their local language or in English. All consecutive patients with suspected intussusception admitted via children emergency of our hospital were enrolled into the study. The inclusion criteria for the population of patients elected to undergo USGHR are all children with ultrasound-diagnosed intussusception. Exclusion criteria included the following: (1) clinical features of perforation and peritonitis. (2) Prolapsed intussusception.

Data retrieved from the case notes included age, sex, duration of symptoms, clinical features, results of treatment, surgical and pathological findings if the patients underwent subsequent laparotomy, complications, and follow-up after discharge. In addition, we collected samples for packed cell volume, electrolytes and cross matching of blood. Other variables collected included the time required to perform the USGHR, number of times procedure was carried out, the volume of fluid used to achieve reduction as well as duration of admission.

\section{Outcome measures and measurement}

The outcome measures were successful reduction, failed reduction with subsequent surgical intervention, perforation during reduction and recurrence of intussusception after treatment.

We defined successful reduction as one in which there was complete disappearance of the intussusceptum with reflux of saline into the ileum.

Failed reduction was defined as one in which the intussusceptum could not be reduced completely or there was perforation of the gut.

Late presentations were those presenting after $24 \mathrm{~h}$ of abdominal pain.

\section{Procedure}

All patients were placed on intravenous infusion of 4.3Dextrose in $1 / 5$ normal saline for hydration, nil per os, intravenous cefuroxime and metronidazole and urinary catheter to prepare the patient for laparotomy in case reduction failed.

Ultrasound scan of the abdomen was performed in the radiology ultrasound suite by the radiology senior registrar with Mindray DC - 7 ultrasound machines with 10 $12 \mathrm{MHz}$ high frequency linear probe to confirm the 
diagnosis of intussusception. After confirmation, an attending radiologist and senior registrar in paediatric surgery performed USGHR. An on-call paediatric surgeon, anaesthetist and peri-operative nurses were informed prior to the procedure in case of complication such as perforation and failed reduction that require surgery.

The USGHR was performed in the following manner with the patient lying supine, an appropriate Foley catheter $(10 \mathrm{~F}-18 \mathrm{~F})$ was inserted into the rectum and balloon inflated. No sedation was $\mathrm{t}$ administered as the patient was held in position by radiology staff. Normal saline, pre-warmed to body temperature was suspended $120 \mathrm{~cm}$ : above the table level (within the range as described by $\mathrm{He}$ et al. [16] and allowed to flow into the colon under gravity. During reduction, the retrograde flow of saline and the regress of intussusceptum were monitored under ultrasound visualization. In addition, the peritoneal cavity was scanned intermittently for the presence of sudden increase in fluid and simultaneous loss of fluid from the colon, indicating bowel perforation. A maximum of 3 attempts were allowed, with each reduction lasting 3 to 5 min with an interval of less than $3 \mathrm{~min}$. If patients were still not reduced after the third attempt, the procedures were stopped immediately and they were taken to theatre immediately for surgical reduction or resection with bowel anastomosis. All patients who had undergone successful USGHR were kept in the ward for observation for at least $24 \mathrm{~h}$ to evaluate for complications and recurrence.

\section{Data analysis}

Data collected were analyzed using Microsoft excel and Statistical Package for Social Scientists version 17 for windows (SPSS Inc. Illinois, Chicago, USA) The data were summarized using means and standard deviation (SD) for continuous variables and frequencies for categorical variables. Inferential statistics with Chi Square test was used to establish association with $p$ value less than 0.05 considered as statistically significant.

\section{Results}

During the study period, we managed 51 children with 56 intussusceptions. Eleven of the patients with eleven intussusceptions were excluded either due to features of peritonitis or intestinal prolapse and were taken to theatre for primary surgery. Only 40 patients with 45 intussusceptions who met the inclusion criteria were analysed. They comprised of 22 males and 18 females giving a male to female ratio of 1.2 to 1 .

Their age ranged from 3 months to 48 months with a mean age of $10.8 \pm 9.1$ and a median of 7 months. Figure 1 shows the distribution of the age of occurrence of intussusception among patients. The peak age incidence was between 7 to 12 months. Most $60 \%(N=27)$ patients presented within $24 \mathrm{~h}$ of onset of abdominal pain while $40 \%(N=18)$ presented after $24 \mathrm{~h}$.

The duration of symptoms ranged from $3 \mathrm{~h}$ to $144 \mathrm{~h}$ with a mean of $40.6 \pm 36.1 \mathrm{~h}$ and a median of $24 \mathrm{~h}$. The clinical features are as shown in Table 1, with the most common symptoms being colicky abdominal pain (100.0\%), vomiting (100.0\%), and palpable abdominal mass $(95.6 \%)$.

Thirty-eight of the intussusception (84.4\%) were ileocolic,4 (8.9\%) were colocolic while $3(6.7 \%)$ were ileoileal intussusception. Table 2 shows the outcome of various types of intussusception. We found no pathologic lead point in our series.

Thirty-eight $(84.4 \%)$ cases were successfully reduced under ultrasound guidance while 7 (15.6\%) cases had partial reduction or failed reduction of intussusceptum necessitating open surgery. Of the failed cases, 2 had bowel perforation during the procedure which was confirmed at

\section{frequency}

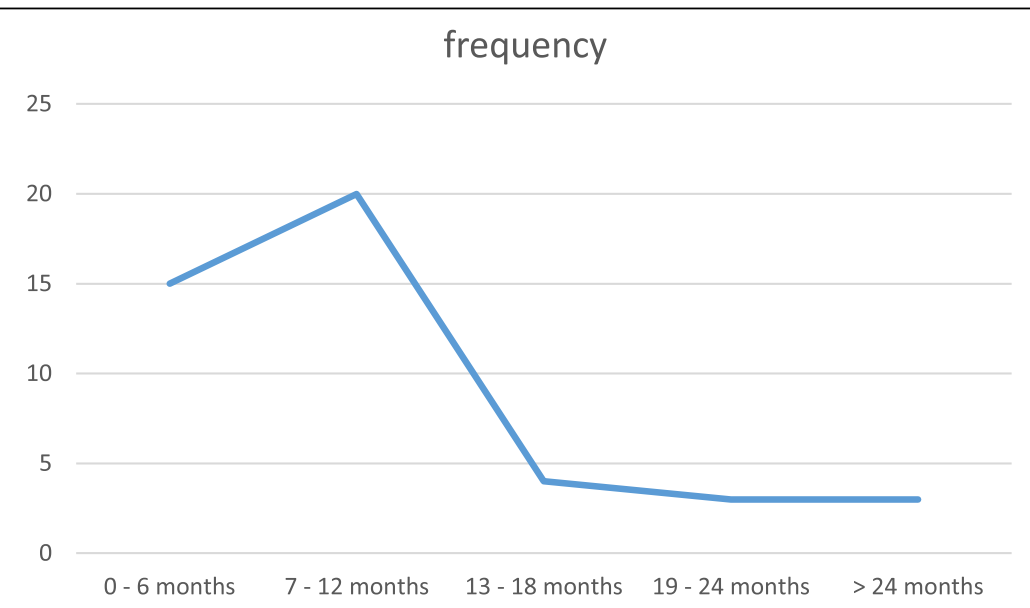

Fig. 1 XXXXX 
Table 1 Clinical features of patients

\begin{tabular}{ll}
\hline Clinical Features & Frequency (\%) \\
\hline Colicky abdominal pain & $45(100 \%)$ \\
Vomiting & $45(100 \%)$ \\
Red currant stool & $36(80.0 \%)$ \\
Abdominal distention & $6(13.3 \%)$ \\
Palpable abdominal mass & $43(95.6 \%)$ \\
Dehydration & $18(40.0 \%)$ \\
Fever & $14(31.1 \%)$ \\
\hline
\end{tabular}

surgery to be due to gangrenous bowel, 2 had gangrene of the bowel without perforation. The remaining three cases had hyperplasic Peyers patches with gross edema of the apex of the intussusceptum. Six patients had bowel resection while one patient had manual reduction. Hydrostatic reduction appears to be more successful in patients with shorter duration of symptoms but this was not statistically significant, $p=0.098$, (Table 3).

In addition, the age and gender did not influence successful reduction of intussusception, $p>0.05$ (Table 3).

Three patients (7.5\%) had recurrent intussusception during follow up. Two patients had 2 episodes of recurrence after the first intussusception at an interval of 3 to 6 months apart while the third patient had a single episode of recurrence within $24 \mathrm{~h}$ after initial reduction. These patients had successful reduction non-operatively. Oral contrast enhanced computerized tomographic scan of the abdomen done for the 2 patients with 2 recurrences revealed no pathology either on the wall or lumen of the intestine. Most (20/38) of the reduction was achieved during the first attempt of the procedure The duration of the procedure ranged between $3 \mathrm{~min}$ to $25 \mathrm{~min}$, with a mean of $8.0 \pm 5.5 \mathrm{~min}$. The mean duration of admission between those who had successful reduction was $2.5 \pm 0.6$ days and those with failed reduction that subsequently had surgery was $9.1 \pm$ 1.5 days. The difference attained statistical significance, $p=0.001$. There was no mortality in our series.

There was a $68 \%(38 / 56)$ decrease in the operative reduction of intussusception following saline hydrostatic reduction under ultrasound guidance.

\section{Discussion}

Non-operative reduction has been the gold standard of treatment of intussusception in developed countries.

Table 2 Outcome of various types of intussusceptions

\begin{tabular}{lll}
\hline Types of intussusception & successful & Non-successful \\
\hline Ileoileal & 2 & 1 \\
Ileocolic & 33 & 5 \\
Colocolic & 3 & 1 \\
\hline
\end{tabular}

Table 3 Factors affecting non-operative reduction of intussusception

\begin{tabular}{llll}
\hline Variables & \multicolumn{2}{c}{ Outcome of non-operative reduction } & $P$ value \\
\cline { 2 - 3 } & Non successful & Successful & \\
\cline { 1 - 2 } $\begin{array}{l}\text { Duration of abdominal } \\
\text { pain in hours }\end{array}$ & & 0.098 \\
$\quad<24$ & $2(7.4 \%)$ & $25(92.6 \%)$ & \\
$>24$ & $5(27.8 \%)$ & $13(72.2 \%)$ & \\
Age (months) & & & 0.182 \\
$0-12$ & $7(20.0 \%)$ & $28(80.0 \%)$ & \\
$13-48$ & $0(0.0 \%)$ & $10(100.0 \%)$ & \\
Gender & & & 1.000 \\
Male & $4(16 \%)$ & $21(84 \%)$ & \\
Female & $3(15 \%)$ & $17(85 \%)$ & \\
\hline
\end{tabular}

Non-operative treatment includes reduction with barium, air or saline enema under fluoroscopic or ultrasound guidance. Since the widespread acceptance of saline reduction under ultrasound guidance, published data indicated high success rates comparable to, or better than fluoroscopic barium or air reduction. The use of USGHR as mainstay of treatment has been slow to take place in many developing nations including Nigeria due to late presentation, misdiagnosis, either lack of or dysfunctional fluoroscopic units and lack of expertise to undertake the procedure in many hospitals $[1,4,9]$. The high mortality rate associated with surgical treatment in developing countries over its developed counterpart has underscored the need for more countries especially those in sub-Saharan Africa to embrace USGHR [4, 15]. There is need for many health professionals to have high index of suspicion to prevent misdiagnosis and public enlightenment on the part of the populace to prevent late presentation so that many patients can benefit from non-operative reduction. In this series, the rate of operative reduction of intussusception decreased by $68 \%$ which was comparable to what was obtained by Wakjira et al. in Ethiopia a developing nation like ours. This implies that health facilities in low resource nations should embrace this non-operative method of managing childhood intussusception.

In the current study, $84.4 \%$ of the reduction was successful. This was similar to the findings of other workers $[3,14,17-19]$ where the success rate of ultrasound guide hydrostatic reduction was more than $82 \%$, which was somewhat more than the success rate of $75 \%$ recorded by Mensah et al. in Ghana [8]. Ogundoyin et al. [1] in Nigeria found a lower successful reduction rate of $55.6 \%$. Wakjira et al. [9] in a recent study were able to achieve 87.2\% reduction rate. However, Sanchez et al. [20] in a subset of 14 children that underwent hydrostatic reduction with saline recorded $100 \%$ success rate. 
Recurrence rate after non-operative reduction intussusception ranges from 5 to $20 \%$ with a mean of $10 \%$ [21]. Recurrent intussusception in which there is a pathologic lead point even has a higher incidence of recurrence in about 8 to $9 \%$ of cases. Half of recurrent intussusception usually occurs within $48 \mathrm{~h}$ but recurrences up to 1.5 years later have been documented [22-24]. In the present study, the recurrence rate was $7.5 \%$, which was consistent with other literature reports [1, 8, 18, 25]. Gray et al. [26] in a meta-analysis of recurrence rate of non-operative reduction of intussusception found a recurrence rate of $7.5 \%$ with saline reduction of intussusception. Recurrent intussusception is amenable to treatment via USGHR, even if it occurs several times [21]. It is worth noting in this series that two children had two late recurrences each at an interval of 3 to 6 months apart with the last episodes being before the age of 18 months. Oral contrast enhanced computed tomography scan of the abdomen confirmed no pathology within or outside the intestine in these children. Non-operative reduction with saline under ultrasound guidance was successful in all recurrent cases in our series. This significant finding stresses the fact that most intussusception are idiopathic and that non operative reduction should be entertained in patients with several late recurrences provide they meet the inclusion criteria for this procedure.

This study finding has shown that age and sex of patients has no role to play in the success of hydrostatic reduction. Our study finding is in agreement with most reports [1, 16, 18]. However, Nayak et al. [17] observed a lower successful reduction in young infants. In the same vein, Eklof et al. [27] in a series of 658 radiologically diagnosed childhood intussusception reported a markedly reduced rate of successful reduction in infants compared with older children. They concluded that the ileocaecal valve for reasons unknown may be more competent in the very young, and makes it practically difficult to allow the flow of contrast into the terminal ileum infants.

The duration of symptoms is an important predictor of outcome of non-operative reduction of intussusception in children Wong et al. [28] found that a mean duration of symptoms of 2.3 days did not affect the success rate of reduction. In contrast, Chung et al. [29] studied the risk factors leading to surgical reduction and found that long-standing duration of symptoms $(>24 \mathrm{~h})$ was a risk factor for failed reduction. Khorana et al. [25] concluded that the presence of intestinal viability rather the long duration of symptoms is an important risk factor for failed reduction. In our series as in some reports $[17,18,25,30]$ the duration of symptoms did not influence successful reduction of intussusception.

The incidence of intestinal perforation during USGHR appears to be low ranging from 0 to $10 \%$ in some series
$[1,3,4,19]$. Bowel perforation due to over insufflation with fluid is a risk but most cases of perforation with reduction are said to have occurred before the procedure and as such, these are 'unavoidable' [17] Most of the perforation occurring during the procedure are due to intestinal gangrene rather than high intraluminal pressure from saline. In our present study as experienced by some researchers $[8,9]$ two patients had intestinal perforations during the procedure. These two cases at laparotomy had bowel gangrene, which was 'missed' during clinical evaluation of the patients. This important finding has underlined the need to careful selection of patients clinically combined with the use of color Doppler ultrasound to assess the vasculature of the bowel prior to reduction. Nevertheless, intestinal perforation due to over inflation or 'missed' bowel gangrene should not discourage the use of sonographic guided hydrostatic reduction of intussusception in resource constraint hospitals where there are no facilities for hydrostatic pressure control.

Some studies $[6,31]$ recorded higher success rate when children were premedicated with chlorpromazine prior to hydrostatic reduction. Flaum et al. [18] found a positive correlation between the use of sedatives and high rate of successful reduction. Bia et al. [32] premedicated all children in their series with wintermin $(1 \mathrm{mg} / \mathrm{kg})$ and recorded up to $96 \%$ success rate. Mensah et al. [8] in Ghana found a success rate of $75 \%$ despite the use of $1-2 \mathrm{mg} /$ $\mathrm{kg}$ of ketamine hydrochloride. We did not give sedatives to the patients in our series. The success rate could not have been better in our study if sedatives were given because majority of those with failed reduction had gangrenous bowel before presentation at our hospital.

\section{Conclusions}

Hydrostatic normal saline enema reduction of intussusception under real time ultrasound is a suitable non-operative technique of managing childhood intussusception with a success rate of $84,4 \%$ in our study. The approach is simple safe and cost effective in a resource constraint environment. We recommend its adoption as the standard technique for managing childhood intussusception in health care centres where facilities and expertise are available.

\section{Limitation}

Our study has some limitations. Most notably was our small size of 51 children with 56 intussusceptions. We had relatively little experience in performing USGHR in our centre.

\section{Abbreviations}

cm: Centimeter; DC-7: Colour Doppler 7; F: French gauge; Mg/kg: Milligram per kilogram body weight; MHz: Mega Hertz; N: Frequency; SD: Standard deviation; SPSS: Statistical package for social sciences; USGHR: Ultrasound guided hydrostatic reduction 


\section{Acknowledgements}

The authors would like to appreciate the effort of resident doctors in the paediatric surgery unit for their role during ultrasound guided saline enema reduction of the intussusception.

\section{Funding}

Funding was essentially provided by the authors as no grant was received for this research.

\section{Availability of data and materials}

The datasets used and or analyzed during the current study are available from the corresponding author on reasonable request.

\section{Authors' contributions}

AOT: Conceived the study and were involved in the design, data collection, analysis and final draft of the manuscript. OCF; Conceived the study and were involved in the design, ultrasound reduction of intussusception, and final draft of the manuscript. KTB: Conceived the study and were involved in design, data collection, and final draft of the manuscript. OAS: Conceived the study and were involved in the design, data collection, and final draft of the manuscript. BIA: Involved in the design, ultrasound reduction of intussusception, data analysis and final draft of the manuscript. OA: Conceived the study and were involved in the design, data collection, and final draft of the manuscript. All authors read and approved the final manuscript.

\section{Authors' information}

1. Ademola Olusegun Talabi. Senior lecturer/Consultant Peadiatric Surgeon, Department of Surgery, Obafemi Awolowo University/Obafemi Awolowo University Teaching Hospitals Complex, lle-Ife, Osun State, Nigeria.

2. Olusola Comfort Famurewa. Associate professor/ Consultant Radiologist, Department of Radiology. Obafemi Awolowo University/Obafemi Awolowo University Teaching Hospitals Complex, Ile-lfe, Osun State, Nigeria. 3. Kayode Taiwo Bamigbola. Consultant Paediatric Surgeon, Department of Surgery, Federal Medical Centre, Owo, Ondo, State.

4. Oludayo Adedapo Sowande. Professor of Paediatric Surgery/ Consultant Surgeon, Department of Surgery, Obafemi Awolowo University/Obafemi Awolowo University Teaching Hospitals Complex, Ile-Ife, Osun State, Nigeria. 5. Babalola Ishmael Afolabi. Consultant Radiologist, Department of Radiology. Obafemi Awolowo Teaching Hospitals Complex, lle-lfe, Osun State, Nigeria. 6. Olusanya Adejuyigbe. Professor of Paediatric Surgery/Consultant Paediatric Surgeon, Department of Surgery, Obafemi Awolowo University/Obafemi Awolowo University Teaching Hospitals Complex, Ile-Ife, Osun State, Nigeria.

\section{Ethics approval and consent to participate}

The Ethics and Research Committee (ERC) of Obafemi Awolowo University Teaching Hospitals Complex, Ile-Ife, Osun State, Nigeria gave approval to conduct the study. REGISTRATION NUMBERS: INTERNATIONAL: IRB/IEC0004553, NATIONAL; NHREC/27/02/2009a. PROTOCOL NUMBER: ERC/2016/08/02. The parents/caregivers of all eligible patients signed assent form on behalf of their wards.

\section{Consent for publication}

Not applicable as no images are used.

\section{Competing interests}

The authors declare that they have no competing interests.

\section{Publisher's Note}

Springer Nature remains neutral with regard to jurisdictional claims in published maps and institutional affiliations.

\section{Author details}

'Department of Surgery, Obafemi Awolowo University, P. O. BOX 5538, lle-lfe, Osun State, Nigeria. ${ }^{2}$ Department of Radiology, Obafemi Awolowo University, lle-Ife, Osun State, Nigeria. ${ }^{3}$ Department of Surgery, Federal Medical Centre, Owo, Ondo State, Nigeria.
Received: 9 December 2017 Accepted: 5 November 2018

Published online: 21 November 2018

\section{References}

1. Ogundoyin OO, Atalabi AM, Lawal TA, Olulana DI. Experience with sonogram - guided hydrostatic reduction of intussusception in children in south West Nigeria. J West Afr Coll Surg. 2013;3:76-88.

2. Khorana J, Singhavejsakul J, Ukarapol N, Laohapensang M, Wakhanrittee J, Patumanond J. Enema reduction of intussusception: the success rate of hydrostatic and pneumatic reduction. Ther Clin Risk Manag. 2015;11:1837-42.

3. Digant SM, Rucha S, Eke S. Ultrasound guided reduction of an ileocolic intussusception by a hydrostatic method by using normal saline enema in paediatric patients: a study of 30 cases. J Clin Diagn Research. 2012;6:1722-5.

4. Talabi AO, Sowande OA, Etonyeaku CA, Adejuyigbe O. Childhood intussusception in Ile - Ife: what has changed? Afr J Paediatr Surg. 2014;10: 239-42.

5. Khong PL, Peh WCG, Lam HL, Chan KL, Cheng W, Lam WWM et al. Ultrasound -guided hydrostatic reduction of childhood intussusception: technique and demonstration. Radiographics 2000;20:e1. https://doi.org/10. 1148/radiographics.20.5.g00see11.

6. Kim YG, Choi BI, Yeon KM, Kim JW. Diagnosis and treatment of childhood intussusception using real time ultra-sonography and saline enema: preliminary report. J Korean Soc Med Ultrasound. 1982;1:66-70.

7. Alebossein M, Babaheidarian P, Salamati P. Comparison of different modalities of reducing childhood intussusception. Iran J Radiol. 2011;8:83-7.

8. Mensah Y, Glover-Addy H, Etwire V, Appeadu-Mensah W, Twum M. Ultrasound guided hydrostatic reduction of intussusception in children at Korle Bu Teaching Hospital: An initial experience. Ghana Med J. 2011;45: 128-31

9. Wakjira E, Sisay S, Zember J, Zewdneh D, Gorfu Y, Kebede T, et al. Implementing ultrasound-guided hydrostatic reduction of intussusception in a low-resource country in sub-Saharan Africa: our initial experience in Ethiopia. Emerg Radiol. 2018;25:1-6.

10. Marinkovic S, Bucarica S, Jeckovic M, Skoric S, Antic J, Starcevic Z. Ultrasound- guided water enema for reduction of childhood intussusception. Med Pregl. 2007;60:605-9.

11. Cheng KL, Saing H, wc P, Mya GH, Cheng W, Khong PL, et al. Childhood intussusception: ultrasound-guided Hartmann's solution hydrostatic reduction or barium enema reduction. J Pediatr Surg. 1997:32:3-6.

12. Bekdash B, Marven SS, Spigg A. Reduction of intussusception: defining a better index of successful non-operative treatment. Pediatr Radiol. 2013;43: 649-56.

13. Ocal S, Cevik M, Boleken ME, Karakas E. A comparison of manual versus hydrostatic reduction in children with intussusception: single-center experience. Afr J Paeditr Surg. 2014;11:184-8.

14. Ahmad MM, Wani MD, Dar HM, Mir IN, Wani HA, et al. An experience of ultrasound guided reduction of intussusception at a tertiary care Centre. $S$ Afr J Surg. 2016:54:10-3.

15. Bode CO. Presentation and management outcome of childhood intussusception in Lagos: a prospective study. Afr J Paed Surg. 2008;5:24-8.

16. He N, Zhang S, Ye X, Zhu X, Zhao Z, Sui X. Risk factors associated with failed sonographically guided saline hydrostatic intussusception reduction in children. J Ultrasound Med. 2014;33:1669-75.

17. Nayak D, Jagdish S. Ultrasound guided hydrostatic reduction of intussusception in children by saline enema. Indian J Surg. 2008;70:8-13.

18. Flaum V, Schneider A, Ferreira CG, Philippe P, Sancho CS, Lacreuse I, et al. Twenty tears experience for reduction of ileocolic intussusceptions by saline enema under ultrasound control. J Pediatr Surg. 2015;51:179-82.

19. Gfoerer S, Fiegel H, Rolle U. Ultrasound-guided reduction of intussusception: a safe and effective method performed by pediatric surgeons. Pediatr Surg Int. 2016;32:679-82

20. Sanchez TR, Doskocil B, Stein-Wexler R. Nonsurgical management of intussusception: retrospective comparison between sonographic and fluoroscopic guidance. J Ultrasound Med. 2015;34:59-63.

21. Ko HS, Schenk JP, Troger J, Rohrschneider WK. Current radiological management of intussusception in children. Eur Radiol. 2007;17:2411-21.

22. Daneman A, Alton DJ, Lobo E, Gravett J, Kim P, Ein SH. Patterns of recurrence of intussusception in children: a 17-year review. Pediatr Radiol. 1998:28:913-9

23. Ein S. Recurrent intussusception in children. J Pediatr Surg. 1975;10:751-5. 
24. Eshel G, Barr J, Heiman J, Bistritzer T, Broide E, Klin B, et al. Incidence of recurrent intussusception following barium versus air enema. Acta Pediatr. 1997;86:545-6

25. Khorana J, Singhavejsakul J, Ukarapol N, Laohapensang M, Siriwongmongkol J, Patumanond J. Prognostic indicators for failed nonsurgical reduction of intussusception. Ther Clin Risk Manag. 2016;12:1231-7.

26. Gray MP, Li SH, Hoffman RG, Gorelic MH. Recurrence rate after intussusception enema reduction: a meta-analysis. Pediatric. 2014;134:110-9.

27. Eklof OA, Johanson L, Lohr G. Childhood intussusception:hydroststic reducibility and incidence of leading point in different age groups. Pediatr Radiology. 1980;10:83-6.

28. Wong CWY, Chan IHY, Chung PHY, Lan LCL, Lam WWM, Wong KKY, et al. Childhood intussusception: 17-year experience at tertiary referral Centre in Hong Kong. Hong Kong Med J. 2015;21:518-23.

29. Chung JL, Kong MS, Lin JN, Wang KL, Lou CC, Wong HF. Intussusception in and children: risk factors leading to surgical reduction. J Formos Med Assoc. 1994;93:481-5.

30. van de Ende ED, Allema JH, Hazebroek FWJ, Breslau PJ. Success with hydrostatic reduction of intussusception in relation to duration of symptoms. Arch Dis Child. 2005;90:1071-2

31. Rohrschneider WK, Troger J. Hydrostatic reduction of intussusception under US guidance. Pediatr Radiol. 1995;25:530-4.

32. Bia YZ, Qu RB, Wang GD, Zhang KR, Li Y, Huang Y, et al. Ultrasound-guided hydrostatic reduction of intussusception by saline enema: a review of 5218 cases in 17 years. Am J Surg. 2006;192:273-5.

Ready to submit your research? Choose BMC and benefit from:

- fast, convenient online submission

- thorough peer review by experienced researchers in your field

- rapid publication on acceptance

- support for research data, including large and complex data types

- gold Open Access which fosters wider collaboration and increased citations

- maximum visibility for your research: over $100 \mathrm{M}$ website views per year

At $\mathrm{BMC}$, research is always in progress.

Learn more biomedcentral.com/submissions 